\title{
Patologias Em Pavimentos de Concreto - Método Icp de Avaliação
}

\author{
Pathology in concrete pavements - PCI evaluation method
}

\author{
Monique Montarroyos Cavalcanti (D) orcid.org/0000-0001-5727-2427 \\ Carlos Welligton Pires Sobrinho (D) orcid.org/0000-0001-5727-2427
}

E-mail do autor principal: Monique Montarroyos Cavalcanti montarroyos.monique@gmail.com

\section{Resumo}

Diversos tipos de manifestações patológicas podem ser observadas em pavimentos rígidos. Neste trabalho foram catalogados os defeitos presentes em placas de concreto de um trecho de uma avenida de grande circulação de veículos do Recife, com o intuito de determinar o estado de conservação da via e compreender como é realizado o método de avaliação ICP (Índice de Condição do Pavimento). A partir do resultado positivo desta avaliação pode-se concluir que pavimentos de concreto podem apresentar alta durabilidade, quando feitas as devidas manutenções.

Palavras-Chave: manifestações patológica; pavimentos rígidos; método de avaliação ICP;

\begin{abstract}
Several types of pathological manifestations can be observed on rigid pavements. In this work were recorded the defects present in concrete slabs of a section from an great vehicles circulation avenue from Recife, with the purpose of determining the road conservation status and understand how the PCI (Pavement Condition Inspection) evaluation method is performed. The conclusion as a positive result of this evaluation was that concrete pavement may present a high durability if made maintenance.
\end{abstract}

Key-words: pathological manifestations; rigid pavements; PCI evaluation method; 


\section{Introdução}

Pavimentos rígidos são conhecidos por sua maior durabilidade em comparação com os pavimentos flexíveis. Porém, manifestações patológicas, ocasionadas muitas vezes pela falta de manutenção da pista, diminuem a sua vida útil. Sendo o transporte rodoviário o principal meio de escoamento da produção nacional, através de sua malha rodoviária, se faz importante a busca por maior entendimento das diversas manifestações patológicas encontradas nas rodovias.

A evolução do comportamento de um pavimento é bastante complexa, pois cada ação provoca uma alteração específica sobre as propriedades dos materiais constituintes dos pavimentos. As degradações funcionam como uma cadeia de acontecimentos, em que cada uma dará origem a novos tipos de degradações e assim sucessivamente, aumentando o percentual de patologias existentes, tanto em extensão quanto em potencial evolutivo. [1]

Uma deficiência ou inexistência de manutenção adequada não raramente culmina em elementos com manifestações patológicas de significativa intensidade, acarretando, não raras vezes, em custos de reparo ou substituição elevados. [2]

Sendo assim, serão apresentadas as principais manifestações patológicas encontradas nos pavimentos rígidos e suas prováveis causas, de modo que fique evidente a importância da conscientização para a manutenção dos pavimentos rodoviários.

Como forma de conhecer o método que avalia pavimentos de concreto, foi realizado um estudo de caso em um trecho da Avenida Conde da Boa Vista e aplicado o método de avaliação ICP, a fim de obter dados sobre a condição estrutural do pavimento neste trecho da via.

\section{Tipos de pavimento de concreto}

Existem diversos tipos de técnicas envolvendo pavimentos rígidos de concreto. Os principais tipos de pavimentos de concreto são:

\subsection{Concreto Simples}

Neste tipo de pavimento apenas o concreto resiste as tensões solicitantes, devendo sua espessura ser dimensionada de modo a garantir que a resistência a tração do concreto não seja ultrapassada. Uma alternativa para melhorar o comportamento estrutural do pavimento é a utilização de barras de transferência. [3]

\subsection{Concreto com armadura distribuída descontínua}

Pavimento dotado de tela de aço posicionada na parte superior das placas, que tem por objetivo diminuir a propagação das fissuras que ocorrem por conta da variação de volume durante o efeito da retração das placas de concreto. Neste tipo de técnica é possível a redução do número de juntas transversais, trazendo vantagens na redução de custos de manutenção e no ganho de qualidade, pois as juntas são pontos de entrada de água, em que diversas manifestações patológicas se iniciam. [3]

\subsection{Concreto Estruturalmente Armados}

Neste tipo de estrutura a malha de aço é posicionada na parte inferior da placa e tem função estrutural, pois resiste aos esforços de tração, fazendo com que a espessura da placa diminua. [3]

\subsection{Concreto Rolado}

Também chamado de CCR - Concreto Compactado a Rolo. Possui baixo consumo de cimento, consistência seca e dura, além de trabalhabilidade, permitindo ser compactado com rolos compressores. Tem menor teor de cimento que os concretos tradicionais, sendo assim mais econômico. Porem a resistência à tração na flexão do CCR é aproximadamente 2 vezes menor que a do concreto simples. [4]

\subsection{Concreto com fibras}

É composto de placas de concreto com adição de fibras. Apresentam maior resistência a fissuração, a impacto e a desgaste, e maior ductibilidade. [4]

\subsection{Concreto Pretendido}

É usado principalmente quando há tráfego pesado, como em pistas e pátios de aeroportos. Nesta técnica a resistência a tração do concreto é controlada pela 
proten-são que comprime o concreto, permitindo a redução na espessura da placa e a tornando mais resistente à água e sem trincas. Outra vantagem são que as juntas transver-sais podem ser espaçadas em até 150 metros. [4]

\subsection{Whitetopping}

Constitui-se na construção de pavimento de concreto apoiado sobre pavimento asfáltico já existente, como forma de reabilitação da via. Normalmente é construído em concreto simples, com espessura variando entre 12 a 15 centímetros. 0 "ultrathin whitetopping" ou whitetop-ping ultra delgado é executado com concreto de alta resistência, com espessura variando entre 5 a 10 centímetros. Neste caso, para evitar a fissuração por retração, as jun-tas são menos espaçadas e de abertura reduzida, e, normalmente, não é preciso material selante. Para viabilizar o uso do whitetopping ultra delgado é necessário aderência entre o pavimento de concreto a ser implantado e o asfáltico, já existente. Ou seja, o pavimento base deve possuir boas condições estruturais, não podendo estar deteriorado. [4]

\section{Juntas nos pavimentos rígidos}

Pavimentos de concreto estão sujeitos ao aparecimento de fissuras transversais e longitudinais, provocadas pelas variações volumétricas do concreto. O controle desse fenômeno se faz necessário, pois ele influência na durabilidade do pavimento, permitindo a entrada indesejável de água. Existem dois tipos de controle de fissuras:[5]

a) Uso de armadura distribuída, sem função estrutural, com a função de manter fortemente ligadas as faces das fissuras, impedindo sua separação.

b) Adoção de seções artificialmente enfraquecidas (juntas), ao longo do pavimento, de modo a forçar o aparecimento de fissuras em local determinado.

\subsection{Juntas transversais}

São construídas no sentido da largura da placa de concreto. Podendo ser:[5]

a) Juntas transversais de retração: decorrentes da expansão volumétrica do concreto. É formada por meio de um corte ou ranhura na superfície do pavimento até profundidade adequada. A ranhura pode ser feita quando o concreto encontra-se plástico ou após seu endurecimento, com emprego de serra circular.

b) Juntas transversais de retração com barras de transferência:

Apresentam função suplementar, pois, além de controlarem a fissuração do concreto, proporcionam uma transferência de carga de uma placa para outra, diminuindo deslocamentos verticais de uma, ou das duas placas, na região das juntas.

\subsection{Juntas longitudinais de construção}

Geralmente são consequência do método construtivo, que possui limitações de largura, mas pode ser necessária a execução de junta longitudinal mesmo que o equipamento não tenha essa limitação. Neste caso a placa será serrada, criando uma junta com objetivo de combater tensões de tração e o empenamento das placas. Para assegurar a ligação entre as faixas devem ser usadas barras de ligação nessas juntas. [3]

\subsection{Selagem das juntas}

A função da selagem é a de impedir a entrada de água e outros materiais, que possam afetar a durabilidade do pavimento. É importante ressaltar que a vida útil dos materiais selantes são, em sua maioria, inferiores a vida útil do pavimento, devendo ser previstas manutenções periódicas. [3]

\section{Patologias observadas em pavimentos rígidos.}

As manifestações patológicas mais encontradas em pavimentos rígidos estão associadas ao emprego da execução e materiais de forma inadequada, acompanhado a falta de manutenção de rotina que esse tipo de estrutura necessita. Podem ocorrer com diferentes frequências e graus de severidade, e tendem a se agravar com o passar do tempo. [5]

Segundo DNIT [6] os defeitos que podem ser observados nos pavimentos rígidos, decorrente de problemas na fundação, de má execução ou do uso do http: / / dx.doi.org/10.25286/repa.v4i1.584 
pavimento são:

\subsection{Alçamento de placas}

É o desnivelamento das placas nas juntas ou nas fissuras transversais e, eventualmente, na proximidade de canaletas de drenagem ou de intervenções no pavimento. [6]

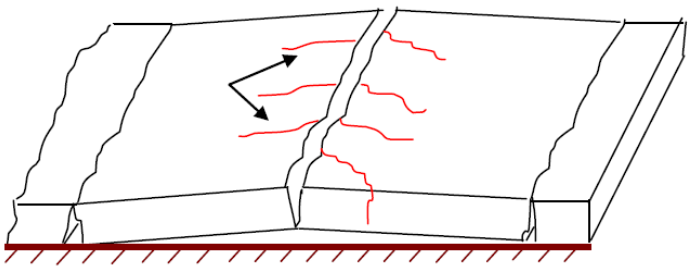

Figura 1: Alçamento de placas [7]

A causa do alçamento de placas é explicada pela expansão (dilatação) linear do pavimento, devido as variações volumétricas de valor significativo, somada a deficiência ou ausência de juntas de dilatação nas placas adjacentes ou nos obstáculos fixos, tais como canaletas de drenagem, encontros de ponte, fundações de prédio e outros. [7]

\subsection{Fissura de canto}

É a fissura que intercepta as juntas a uma distância de no máximo 1,8 metros das bordas, ou juntas do pavimento (longitudinal e transversal), medida a partir do seu canto. Geralmente está fissura atinge toda a espessura da placa [7]

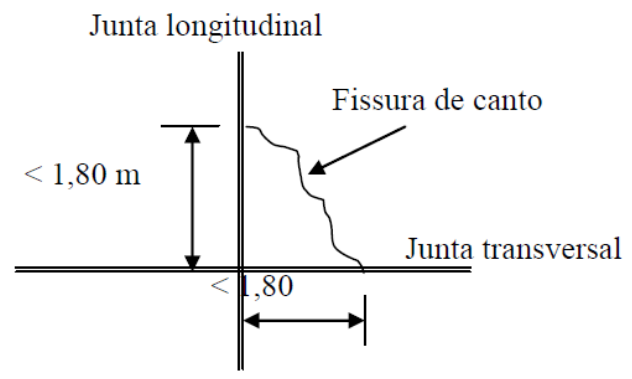

Figura 2: Fissura de canto [7]

São decorrentes da falta ou deficiência de dispositivos de transmissão de carga nas juntas, como barras de transferência, encaixe tipo macho-fêmea ou pela falta de entrosagem dos agregados, no caso da junta ter sido executada por serragem. Outras causas que também podem levar ao aparecimento de fissuras no canto são o subdimensionamento da espessura do pavimento, recalque diferencial da fundação da estrutura, e o empenamento dos cantos da placa, devido a variações térmicas e de umidade entre a parte superior e inferior da placa. [7]

\subsection{Placa dividida}

É quando a placa apresenta fissuras que a dividem em quatro ou mais partes. Se deve por conta de fissuras que ocorrem em diversos sentidos da placa (transversal, diagonal, longitudinal), a causa está relacionada com a origem das diversas fissuras. Considerando a existência de várias fissuras, em diferentes sentidos, as causas podem ter como origem deficiências no suporta da fundação do pavimento, subdimensionamento da espessura da placa, ou fadiga do concreto. [7]

\subsection{Escalonamento ou degrau nas juntas}

Se dá pela ocorrência de deslocamentos verticais diferenciados e permanentes entre uma placa e outra adjacente, na região da junta. [6]

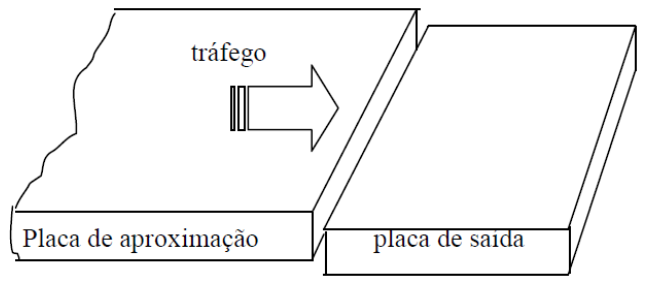

Figura 3: Escalonamento ou degrau nas juntas [7]

É causado pela perda progressiva da eficiência nesta junta, ou seja, a perda da capacidade de uma placa transmitir uma carga à placa adjacente, que ocorre por conta da falta ou deficiência dos dispositivos capazes de garantir esta transmissão de carga nas juntas, tais como barras de transferência, encaixe tipo macho-fêmea. Também pode ser causada por conta de deficiências na sub-base ou pelo dimensionamento de placas de pequenas dimensões, aliado à passagem de tráfego pesado. Além de reduzir o conforto e a segurança do tráfego e provocar danos nos veículos, estes degraus contribuem para a redução da vida útil do pavimento. [7]

\subsection{Falha na selagem das juntas}

Qualquer avaria no material selante que possibilite o acumulo de material incompressível na junta ou que permita a infiltração de água. As principais falhas observadas são: [6]

- Rompimento por tração ou compressão

- Extrusão de material 
- Crescimento de vegetação

- Endurecimento (oxidação) do material

- Perda de aderência às placas de concreto

- Quantidade deficiente de selante

Este tem sido a patologia mais presente nos pavimentos de concreto, sendo normalmente motivado por falhas na execução da selagem, ou pela escolha de material selante inadequado ou de baixa vida útil. [7]

\subsection{Desnível acostamento}

\section{pavimento}

É o degrau formado entre o acostamento e a borda do pavimento, geralmente acompanhado de uma separação entre eles. [6]

\subsection{Fissuras lineares}

São fissuras que atingem toda a espessura da placa, dividindo-a em duas ou mais partes. Quando as fissuras dividem a placa em quatro ou mais partes a patologia é conhecida como placa dividida. [6]

- Fissuras transversais - que ocorrem na direção da largura da placa, perpendicular ao eixo longitudinal do pavimento. São provocadas pela retração hidráulica ou perda d'água. Aparecem depois do concreto ter endurecido e suas possíveis causas são: [7]
a) Cura deficiente
b) Atraso na serragem das juntas transversais
c) Profundidade insuficiente do corte da junta
d) Placas com comprimento acima do adequado
e) Insuficiência de suporte da fundação
f) Subdimensionamento da espessura da placa

Nas fissuras transversais localizadas próximas a junta transversal, pode indicar como causa a ineficiência ou má colocação das barras de transferência.

- Fissuras longitudinais - que ocorrem na direção do comprimento da placa, paralela ao eixo 5 longitudinal do pavimento. São provocadas por: [7]

a) Largura excessiva da placa

b) Empenamento da placa no sentido transversal, com o levantamento das bordas longitudinais

c) Profundidade insuficiente do corte da junta longitudinal

- Fissuras diagonais - inclinadas, interceptam as juntas do pavimento a uma distância maior que a metade do comprimento dessas juntas ou bordas. São provocadas por deficiência no suporte da fundação, ou decorrentes da formação simultânea de fissuras transversais e longitudinais. [7]

\subsection{Grandes reparos}

Área maior que $0,45 \mathrm{~m}^{2}$, que foi removida e posteriormente preenchida com material de enchimento. [6]

\subsection{Pequenos reparos}

Área menor ou igual a $0,45 \mathrm{~m}^{2}$, que foi removida e posteriormente preenchida com material de enchimento. [6]

\subsection{Desgaste superficial}

Deslocamento da argamassa superficial, fazendo com que os agregados apareçam na superfície do pavimento, e com o tempo fiquem com a superfície polida. [6]

São provocados pelas seguintes causas: [7]

- Emprego de concreto de baixa qualidade

- Emprego de agregados sujos ou com pó aderente

- Excesso de água de mistura no concreto

- Deslocamento da argamassa de cobrimento, devido ao acumulo de água na superfície.

Esta patologia tende a progredir com o tempo, tornando o pavimento desconfortável ao tráfego, além de originar a formação de buracos nas placas.

http://dx.doi.org/10.25286/repa.v4i1.584 


\subsection{Bombeamento}

Consiste na expulsão de finos plásticos existentes no solo da fundação do pavimento, através das juntas, bordas, ou trincas, durante a passagem de cargas solicitantes. Os finos bombeados têm forma de lama fluida, sendo identificados pela presença de manchas terrosas ao longo das juntas. Provoca inicialmente o amolecimento da fundação e posteriormente o descalçamento das placas na área afetada. Com isso as placas sofrem maiores tensões com a passagem do tráfego, acima do que foi considerado no dimensionamento do pavimento, acelerando o processo de fadiga e provocando sua ruptura precoce. $O$ bombeamento pode também ser causado pela ausência de uma sub-base ou por sua execução de forma inadequada. [7]

\subsection{Quebras localizadas}

São áreas das placas que encontram-se trincadas e partidas em pequenos pedaços, com formas variadas, situando-se, geralmente, entre uma trinca e uma junta ou entre duas trincas próximas entre si. [8]

\subsection{Passagem de nível}

Consistem em depressões ou elevações próximas aos trilhos. Decorrentes de projeto inadequado ou de execução deficiente do pavimento. [7]

\subsection{Fissuras (rendilhado) e escamação}

São fissuras capilares que ocorrem apenas na superfície da placa, e apresentam tendência de se interceptarem, formando ângulos de $120^{\circ}$. A escamação decorre do descolamento da camada superficial fissurada, podendo ser proveniente do desgaste superficial. [6]

\subsection{Fissuras de retração plástica}

São fissuras pouco profundas (superficiais) e de comprimento limitado. Sua incidência costuma ser aleatória, formando ângulos de $45^{\circ}$ a $60^{\circ} \mathrm{com}$ o eixo longitudinal da placa. A causa desse tipo de fissura é a retração plástica, que ocorre no concreto antes do início da pega. É decorrente da execução do pavimento em ambiente de muita insolação, ação de ventos e baixa umidade relativa do ar. [7]

\subsection{Esborcinamento ou quebra de canto}

São quebras que aparecem nos cantos das placas, tendo forma de cunha, e ocorrem em uma distância não superior a $60 \mathrm{~cm}$ do canto. Difere da fissura de canto, pelo fato de interceptar a junta num determinado ângulo (em forma de cunha). [6]

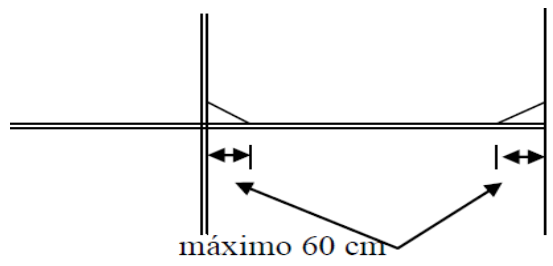

Figura 4: quebra de canto [7]

São causadas pela retirada das fôrmas nestes locais de maneira brusca, ou com o concreto ainda com baixa resistência. Podem também ser decorrentes da utilização imprópria de veículos pesados na via. [7]

\subsection{Esborcinamento de juntas}

Se caracteriza pela quebra das bordas da placa nas juntas, com comprimento máximo de $60 \mathrm{~cm}$, não atingindo toda espessura da placa.

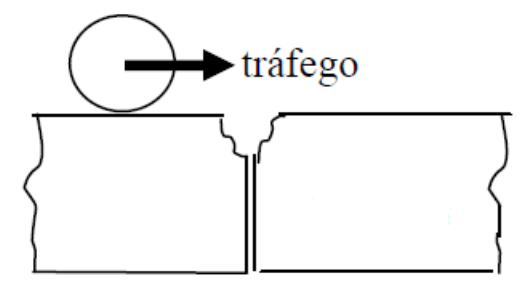

Figura 5: Esborcinamento de juntas [7]

Podem ter como causas: [7]

- Remoção precipitada das fôrmas

- Serragem prematura da junta

- Infiltração de materiais incompressíveis na junta

\subsection{Placa "bailarina"}

É a placa cuja movimentação vertical é visível sob ação do tráfego, principalmente na região das juntas. Tem como causas as perdas localizadas ou generalizadas do suporte da fundação, aliadas à existência de juntas ineficientes e à ação de tráfego pesado. [7] 


\subsection{Assentamento}

Caracteriza-se pelo afundamento do pavimento, criando ondulações superficiais de grande extensão, podendo o pavimento permanecer íntegro. Pode ser decorrente: [7]

- Deficiência ou falta de uniformidade do suporte da fundação

- Projeto ou execução deficiente da sub-base

\subsection{Buracos}

São reentrâncias côncavas observadas na superfície da placa, provocadas pela perda de concreto no local, apresentando área e profundidade definidas. Oriundas da progressão de outros defeitos, como fissuras profundas, escamação, lascamento, desgaste superficial, ou pelo emprego de concreto de baixa qualidade. [7]

\section{Grau de severidade do defeito}

De acordo com DNIT [9] o grau de severidade de um defeito de pavimento se dá segundo sua dimensão, condição ou com a sua influência no conforto, segurança e escoamento do tráfego.

A avaliação objetiva consiste na avaliação estrutural do pavimento baseada na determinação do ICP (índice de condição do pavimento). O ICP fornece informações para verificação das condições da rodovia, estabelecendo dados base para medidas de manutenção, prevenção e recuperação da estrutura. [8]

A avaliação subjetiva consiste em avaliar as condições do pavimento quanto ao conforto de tráfego, por meio de observações e atribuição de notas, realizadas por avaliadores experientes que trafegam sobre a via. [10]

\section{$5.1 \quad$ ICP}

O ICP é um número que indica o estado de conservação em que se encontra $o$ pavimento. Baseado em metodologia simples e eficiente, desenvolvida pelo U.S. Army Construction Engineering Research Laboratory (C.E.R.L.). Com base neste índice são definidas as estratégias para serviços de manutenção e recuperação dos pavimentos. Geralmente os pavimentos ou trechos de pavimentos que apresentam ICP igual ou maior que 70 não necessitam de programas de recuperação, e aqueles com o ICP menor que 40 são considerados deficientes ou praticamente destruídos. [5]

De acordo com DNIT [8] para se calcular o ICP de uma amostra, subtrai-se de 100 (que é o valor do ICP, quando não há nenhum defeito visível na amostra) um somatório de valores deduzíveis (CVD), que é calculado em função dos tipos de graus de severidade de placas defeituosas visíveis [grau baixo (B), médio (M) ou alto (A)]. Antes de ser subtraído o CVD deve ser corrigido, obtendo o VDC, de acordo com o número de valores deduzíveis e sua influência na condição estrutural do pavimento. $O$ passo a passo para 0 cálculo do ICP é:

a) Obter o CVD de cada tipo de defeito/patologia, utilizando as curvas apresentadas em anexo na norma DNIT 062/2004-PRO-Pavimento RígidoAvaliação objetiva de pavimentos rígidosProcedimento.

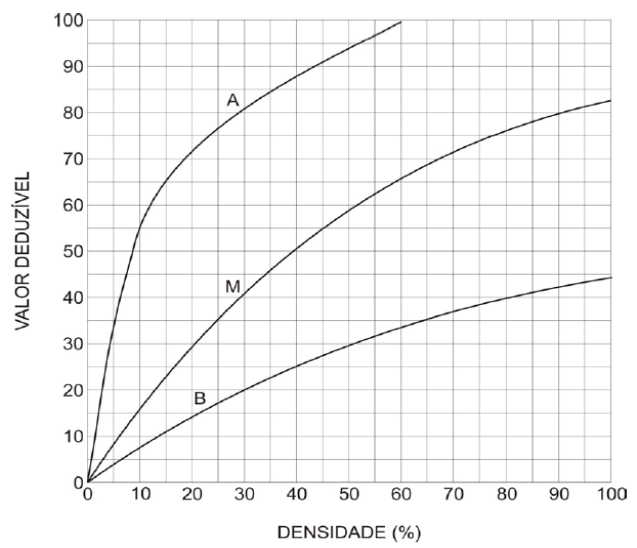

Figura 6: Curva de valor deduzível do defeito 1 alçamento de placas. [8]

b) Somar os CVD de todos os defeitos/patologias.

c) Corrigir o $\Sigma C V D$, obtendo o VDC, utilizando o gráfico de valor deduzível corrigido apresentado em anexo na norma DNIT 062/2004-PROPavimento Rígido-Avaliação objetiva de pavimentos rígidos-Procedimento.

d) Achar o valor do ICP pela formula:

$$
\mathrm{ICP}=100-\mathrm{VDC}
$$

De posse do valor do ICP, pode ser observado em que conceito está inserido a amostra em análise, ou seja, em que estado encontra-se aquele trecho da estrutura. A Tabela 1 define os conceitos de acordo com os limites de ICP.

http://dx.doi.org/10.25286/repa.v4i1.584 
Tabela 1: Conceito de ICP [6]

\begin{tabular}{|c|c|}
\hline CONCEITO & LIMITES \\
\hline EXCELENTE & $85<$ ICP $\leq 100$ \\
\hline MUITO BOM & $70<$ ICP $\leq 85$ \\
\hline BOM & $55<$ ICP $\leq 70$ \\
\hline RAZOÁVEL & $40<$ ICP $\leq 55$ \\
\hline RUIM & $25<$ ICP $\leq 40$ \\
\hline MUITO RUIM & $10<$ ICP $\leq 25$ \\
\hline DESTRUÍDO & ICP $\leq 10$ \\
\hline
\end{tabular}

\section{Análise de trecho da Avenida Conde da Boa Vista}

A Avenida Conde da Boa Vista possui grande importância para a circulação de veículos em direção ao centro do Recife, possuindo uma extensão aproximada de 1700 metros e faixas de trafego misto, que somam uma largura total de 18 metros.

Chamada de Rua Formosa até o ano de 1870, quando recebeu o nome de Avenida Conde da Boa Vista em homenagem a Francisco do Rego Barros, presidente da província de Pernambuco no período de
1837-1844.

A primeira pavimentação de concreto da Avenida aconteceu entre 1954-1959. Um novo projeto de dimensionamento do pavimento de concreto foi desenvolvido em 2007, com o objetivo de permitir sua inserção no corredor Leste-Oeste.

O trecho analisado da Avenida possui 6 faixas de aproximadamente 170 metros de comprimento cada, com faixas centrais de uso exclusivo do transporte público (Faixas 2, 3, 4 e 5) e as faixas laterais (Faixas 1 e 6) para uso de veículos de passeio, com 29 placas por faixa, totalizando 174 placas. Caminhando no sentido Centro-Derby o início do trecho situa-se em frente as tintas Sherwin-Williams (latitude: $8^{\circ} 3^{\prime} 25.28^{\prime \prime}$; ; longitude: $34^{\circ} 53^{\prime} 30.33^{\prime \prime O}$ ) e seu fim é marcado pela loja Handara (latitude: $8^{\circ} 3^{\prime} 23.64 " S$; longitude: $34^{\circ} 53^{\prime} 35.82^{\prime \prime O}$ ).

Foi feita a inspeção visual de placa em placa, observando as manifestações patológicas apresentadas no pavimento. A maioria das placas observadas no trecho possuem desgaste superficial e falha na selagem das juntas, ocasionadas pelo uso constante da via por um alto fluxo de veículos. A Tabela 2 mostra o levantamento das manifestações patológicas feito no trecho analisado. 
Revista de Engenharia e Pesquisa Aplicada (2019) Vol.4 No.1.

Tabela 2: Levantamento das manifestações patológicas encontradas nas placas de concreto de trecho da Avenida Conde da Boa Vista.

\begin{tabular}{|c|c|c|c|c|c|c|c|c|c|c|c|}
\hline \multicolumn{2}{|c|}{ FAIXA 1} & \multicolumn{2}{|c|}{ FAIXA 2} & \multicolumn{2}{|c|}{ FAIXA 3} & \multicolumn{2}{|c|}{ FAIXA 4} & \multicolumn{2}{|c|}{ FAIXA 5} & \multicolumn{2}{|c|}{ FAIXA 6} \\
\hline Placa & Defeito & Placa & Defeito & Placa & Defeito & Placa & Defeito & Placa & Defeito & Placa & Defeito \\
\hline 1 & $5 ; 10$ & 1 & $5 ; 10 ; 17 ; 20$ & 1 & - & 1 & $5 ; 9 ; 10$ & 1 & $5 ; 10$ & 1 & $5 ; 10$ \\
\hline 2 & $5 ; 10 ; 20$ & 2 & $5 ; 10 ; 20$ & 2 & - & 2 & $5 ; 10$ & 2 & $5 ; 10$ & 2 & $5 ; 10$ \\
\hline 3 & $5 ; 10$ & 3 & $5 ; 10 ; 16$ & 3 & 20 & 3 & $5 ; 10$ & 3 & $5 ; 10$ & 3 & $5 ; 10$ \\
\hline 4 & $5 ; 10$ & 4 & $5 ; 10 ; 17$ & 4 & $5 ; 10 ; 17$ & 4 & $5 ; 10$ & 4 & $5 ; 10$ & 4 & $5 ; 10$ \\
\hline 5 & 14 & 5 & $5 ; 20$ & 5 & 10 & 5 & $5 ; 10$ & 5 & $5 ; 10$ & 5 & $5 ; 10$ \\
\hline 6 & 10 & 6 & - & 6 & 10 & 6 & $5 ; 10$ & 6 & $5 ; 10$ & 6 & $5 ; 10$ \\
\hline 7 & $5 ; 10 ; 17$ & 7 & 20 & 7 & - & 7 & $5 ; 10$ & 7 & $5 ; 10$ & 7 & $5 ; 10$ \\
\hline 8 & $5 ; 9 ; 10$ & 8 & $8 ; 20$ & 8 & 10 & 8 & $5 ; 10$ & 8 & $5 ; 10$ & 8 & $5 ; 10$ \\
\hline 9 & 20 & 9 & - & 9 & $10 ; 20$ & 9 & $5 ; 10$ & 9 & $5 ; 10$ & 9 & $5 ; 10$ \\
\hline 10 & 5 & 10 & $5 ; 10 ; 17$ & 10 & 20 & 10 & 5 & 10 & 5 & 10 & $5 ; 10$ \\
\hline 11 & $5 ; 10 ; 17 ; 20$ & 11 & 10 & 11 & 5;9;10;20 & 11 & $5 ; 10 ; 12$ & 11 & $5 ; 10$ & 11 & $5 ; 10$ \\
\hline 12 & $10 ; 17 ; 20$ & 12 & 7 & 12 & - & 12 & 5 & 12 & 5 & 12 & 5 \\
\hline 13 & 10 & 13 & 20 & 13 & - & 13 & $5 ; 10 ; 17$ & 13 & $5 ; 10$ & 13 & $5 ; 10$ \\
\hline 14 & $7 ; 10$ & 14 & $10 ; 14 ; 17$ & 14 & 2 & 14 & 5 & 14 & $5 ; 10$ & 14 & $5 ; 10$ \\
\hline 15 & 10 & 15 & $9 ; 10 ; 20$ & 15 & $5 ; 20$ & 15 & 5 & 15 & 5 & 15 & $5 ; 10$ \\
\hline 16 & 10 & 16 & $9 ; 10 ; 16$ & 16 & 5 & 16 & $5 ; 10$ & 16 & 5 & 16 & $5 ; 10$ \\
\hline 17 & $5 ; 10$ & 17 & $5 ; 10$ & 17 & $5 ; 10$ & 17 & $5 ; 10$ & 17 & $5 ; 10$ & 17 & $5 ; 10$ \\
\hline 18 & $5 ; 9 ; 10$ & 18 & $5 ; 7 ; 10$ & 18 & $5 ; 17$ & 18 & $5 ; 10 ; 16$ & 18 & $5 ; 10$ & 18 & $5 ; 10$ \\
\hline 19 & $9 ; 10 ; 14 ; 20$ & 19 & $5 ; 17$ & 19 & 5 & 19 & $5 ; 9 ; 10$ & 19 & $5 ; 10$ & 19 & $5 ; 10$ \\
\hline 20 & $10 ; 17 ; 20$ & 20 & $5 ; 10 ; 20$ & 20 & 5 & 20 & $5 ; 10$ & 20 & 5 & 20 & $5 ; 10$ \\
\hline 21 & $5 ; 10 ; 20$ & 21 & - & 21 & 9;10 & 21 & 5 & 21 & $5 ; 10$ & 21 & $5 ; 10$ \\
\hline 22 & 9;10 & 22 & - & 22 & 10 & 22 & $5 ; 7 ; 10$ & 22 & $5 ; 10$ & 22 & $5 ; 10$ \\
\hline 23 & 10 & 23 & - & 23 & 10 & 23 & 5 & 23 & $5 ; 10$ & 23 & $5 ; 10$ \\
\hline 24 & $5 ; 10$ & 24 & - & 24 & 9;10 & 24 & 5 & 24 & $5 ; 10$ & 24 & $5 ; 10$ \\
\hline 25 & $5 ; 10$ & 25 & - & 25 & $7 ; 14 ; 10$ & 25 & $5 ; 10$ & 25 & $5 ; 10$ & 25 & $5 ; 10$ \\
\hline 26 & $5 ; 10 ; 17 ; 20$ & 26 & $10 ; 20$ & 26 & 10 & 26 & 5 & 26 & $5 ; 10$ & 26 & $5 ; 10$ \\
\hline 27 & $1 ; 5 ; 10$ & 27 & 20 & 27 & 7 & 27 & 5 & 27 & 5 & 27 & $5 ; 10$ \\
\hline 28 & $5 ; 10$ & 28 & $5 ; 9 ; 10$ & 28 & $5 ; 10$ & 28 & 5 & 28 & $5 ; 10$ & 28 & $5 ; 10$ \\
\hline 29 & $5 ; 10$ & 29 & $10 ; 20$ & 29 & $10 ; 20$ & 29 & 5 & 29 & $1 ; 5 ; 10 ; 12$ & 29 & $5 ; 10$ \\
\hline \multicolumn{12}{|c|}{ LEGENDA DEFEITOS } \\
\hline 1 & \multicolumn{3}{|c|}{ Alçamento de placas } & 8 & \multicolumn{3}{|c|}{ Grandes reparos } & 15 & \multicolumn{3}{|c|}{$\begin{array}{l}\text { Fissuras de retração } \\
\text { plástica }\end{array}$} \\
\hline 2 & \multicolumn{3}{|c|}{ Fissura de canto } & 9 & \multicolumn{3}{|c|}{ Pequenos reparos } & 16 & \multicolumn{3}{|c|}{ Quebra de canto } \\
\hline 3 & \multicolumn{3}{|c|}{ Placa dividida } & 10 & \multicolumn{3}{|c|}{ Desgaste superficial } & 17 & \multicolumn{3}{|c|}{ Esborcinamento de juntas } \\
\hline 4 & \multicolumn{3}{|c|}{ Escalonamento nas juntas } & 11 & \multicolumn{3}{|c|}{ Bombeamento } & 18 & \multicolumn{3}{|c|}{ Placa bailarina } \\
\hline 5 & \multicolumn{3}{|c|}{ Falha na selagem das juntas } & 12 & \multicolumn{3}{|c|}{ Quebras localizadas } & 19 & \multicolumn{3}{|c|}{ Assentamento } \\
\hline 6 & \multicolumn{3}{|c|}{ Desnível pavimento-acost. } & 13 & \multicolumn{3}{|c|}{ Passagem de nível } & 20 & Buracos & & \\
\hline 7 & Fissuras line & ares & & 14 & Fissuras su & perficiai & & - & Nada visua & lizado & \\
\hline
\end{tabular}




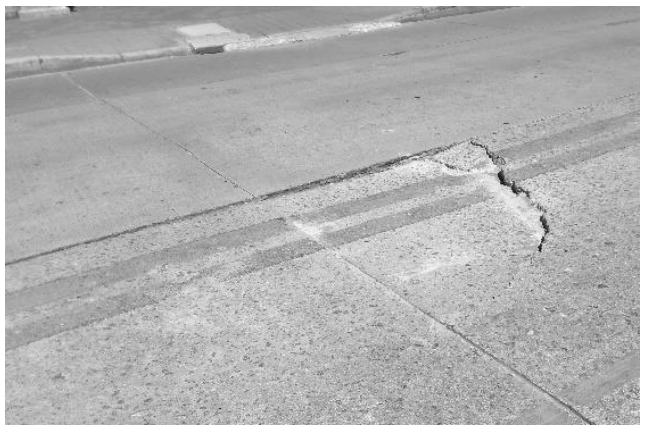

Foto 1: Quebras localizadas e desgaste superficial

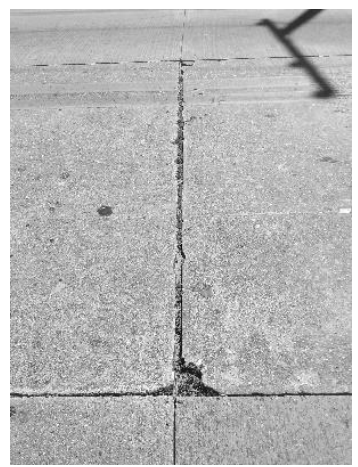

Foto 2: Falha na selagem das juntas e quebra de canto

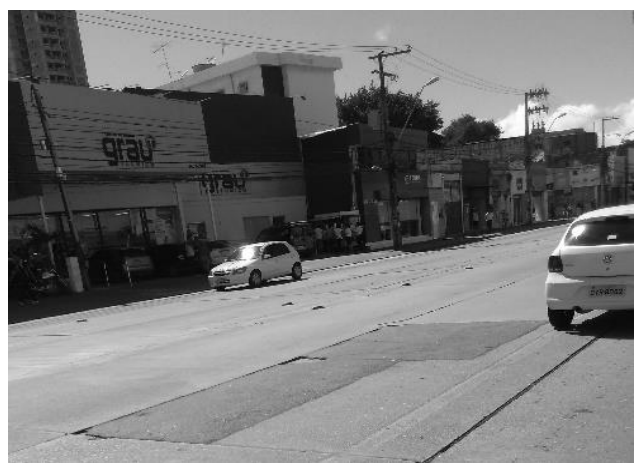

Foto 3: Grandes reparos

\subsection{Cálculo do ICP da Faixa 1 - Sentido Centro-Derby}

É a faixa do rolamento lateral, ao lado da calçada de pedestres, e que fica no sentido Centro-Derby, em que há trafego de veículos de passeio. Como não existe trafego de veículos de transporte público nesta faixa, as placas não apresentam defeitos significativos que comprometam a estrutura do pavimento e o fluxo de veículos. A maioria das placas apresentam desgaste superficial, por serem estruturas com muitos anos de uso, falha nas selagens das juntas, por erros na execução ou falta de manutenção (o selante usado nas juntas possui vida útil bem menor que a do pavimento, sendo essencial sua manutenção de tempos em tempos). A partir dos dados da Tabela $2 \mathrm{e}$ seguindo as recomendações para o cálculo do ICP, podemos determinar o peso de cada defeito encontrado na Faixa 1 (CVD), a soma dos defeitos $(\Sigma C V D)$ e seu valor corrigido (VDC), para assim encontrar o conceito da Faixa 1.

Tabela 3: ICP da Faixa 1

\begin{tabular}{|c|c|c|c|c|}
\hline \multicolumn{5}{|c|}{ ICP Faixa 1} \\
\hline $\begin{array}{c}\text { Tipo } \\
\text { de } \\
\text { defeit } \\
0\end{array}$ & $\begin{array}{c}\text { Grau de } \\
\text { severidad } \\
\text { e }\end{array}$ & $\begin{array}{c}\mathbf{N}^{\circ} \text { de } \\
\text { placas } \\
\text { afetada } \\
\mathbf{S}\end{array}$ & $\begin{array}{c}\% \text { de } \\
\text { placas } \\
\text { afetada } \\
\mathrm{s}\end{array}$ & $\begin{array}{c}\text { Valor } \\
\text { deduzíve } \\
\text { I (CVD) }\end{array}$ \\
\hline 1 & Baixo & 1 & $3 \%$ & 2 \\
\hline 5 & Médio & 17 & $59 \%$ & 4 \\
\hline 7 & Baixo & 1 & $3 \%$ & 3 \\
\hline 9 & Baixo & 4 & $14 \%$ & - \\
\hline 10 & Médio & 26 & $90 \%$ & 10 \\
\hline 14 & Baixo & 2 & $7 \%$ & 2 \\
\hline 17 & Baixo & 5 & $17 \%$ & 4 \\
\hline 20 & Baixo & 7 & $24 \%$ & - \\
\hline \multicolumn{4}{|c|}{$\sum$ CVD } & 25 \\
\hline \multicolumn{4}{|c|}{ Valor corrigido - VDC } & 13 \\
\hline \multicolumn{4}{|c|}{$I C P=100-V D C$} & 87 \\
\hline \multicolumn{4}{|c|}{ CONCEITO } & EXCELENTE \\
\hline
\end{tabular}

Algumas observações sobre o cálculo do ICP da Faixa 1 são que em relação ao tipo de defeito 9 pequenos reparos, a porcentagem de placas afetadas quando jogada na curva específica do defeito resulta em um valor insignificante, não obtendo valor dedutível para essa patologia. $\mathrm{E}$ em relação ao defeito 20 - buracos, segundo norma, essa patologia é apenas catalogada, mas não entra no cálculo do ICP, sendo seu valor dedutível não considerado. Fazendo todo o procedimento de cálculo chega-se à conclusão que a faixa em questão encontra-se com ICP de 86, que resulta em conceito de excelente pavimento rígido.

\subsection{Cálculo do ICP da Faixa 2 - Sentido Centro-Derby}

A Faixa 2 localiza-se entre as Faixas 1 e 3, também no sentido Centro-Derby. É uma das faixas de uso exclusivo do transporte público. Possuem um desgaste superficial mais intenso, se comparado a faixa de uso de veículos de passeio, devido ao fluxo de veículos de maior carga. Pode ser observado também uma maior quantidade de pequenos buracos, devido a remoção de tachões, ou pela saída de agregados presente nas placas, por conta do processo 
de desgaste superficial, e um esborcinamento das juntas mais intenso.

Tabela 4: ICP da Faixa 2

\begin{tabular}{|c|c|c|c|c|}
\hline \multicolumn{5}{|c|}{ ICP Faixa 2} \\
\hline $\begin{array}{c}\text { Tipo } \\
\text { de } \\
\text { defeito }\end{array}$ & $\begin{array}{c}\text { Grau de } \\
\text { severidade }\end{array}$ & $\begin{array}{c}\mathbf{N}^{\circ} \text { de } \\
\text { placas } \\
\text { afetadas }\end{array}$ & $\begin{array}{c}\% \text { de } \\
\text { placas } \\
\text { afetadas }\end{array}$ & $\begin{array}{c}\text { Valor } \\
\text { deduzível } \\
\text { (CVD) }\end{array}$ \\
\hline 5 & Médio & 11 & $38 \%$ & 4 \\
\hline 7 & Baixo & 2 & $7 \%$ & 5 \\
\hline 8 & Baixo & 1 & $3 \%$ & 1 \\
\hline 9 & Baixo & 3 & $10 \%$ & - \\
\hline 10 & Médio & 15 & $52 \%$ & 9 \\
\hline 14 & Baixo & 1 & $3 \%$ & 1 \\
\hline 16 & Baixo & 2 & $7 \%$ & 2 \\
\hline 17 & Baixo & 5 & $17 \%$ & 4 \\
\hline 20 & Baixo & 11 & $38 \%$ & - \\
\hline \multicolumn{4}{|c|}{$\sum$ CVD } & 26 \\
\hline \multicolumn{4}{|c|}{ Valor corrigido - VDC } & 14 \\
\hline \multicolumn{4}{|c|}{$I C P=100-V D C$} & 86 \\
\hline \multicolumn{4}{|c|}{ CONCEITO } & EXCELENTE \\
\hline
\end{tabular}

As mesmas observações, sobre os defeitos 9 e 20, apresentadas na Faixa 1 são aqui também pontuadas. Além de que algumas placas da Faixa não apresentavam defeitos visíveis, e outras tinham sobre elas umas das paradas de ônibus da avenida, não sendo possível suas análises.

\subsection{Cálculo do ICP da Faixa 3 - Sentido Centro-Derby}

A Faixa 3 localiza-se no corredor central de ônibus, no sentido Cidade-Derby, recebe grande influência da carga dos transportes coletivos, que resulta em maior incidência de manifestações patológicas, que neste caso não foi observado, provavelmente devido a via recentemente ter passado por manutenções e trocas de placas.
Tabela 5: ICP da Faixa 3

\begin{tabular}{|c|c|c|c|c|}
\hline \multicolumn{5}{|c|}{ ICP Faixa 3} \\
\hline $\begin{array}{c}\text { Tipo } \\
\text { de } \\
\text { defeito }\end{array}$ & $\begin{array}{c}\text { Grau de } \\
\text { severidade }\end{array}$ & $\begin{array}{c}\mathrm{N}^{\circ} \text { de } \\
\text { placas } \\
\text { afetadas }\end{array}$ & $\begin{array}{c}\% \text { de } \\
\text { placas } \\
\text { afetadas }\end{array}$ & $\begin{array}{c}\text { Valor } \\
\text { deduzível } \\
\text { (CVD) }\end{array}$ \\
\hline 2 & Baixo & 1 & $3 \%$ & 3 \\
\hline 5 & Médio & 9 & $31 \%$ & 4 \\
\hline 7 & Baixo & 2 & $7 \%$ & 4 \\
\hline 9 & Baixo & 3 & $10 \%$ & - \\
\hline 10 & Médio & 15 & $52 \%$ & 9 \\
\hline 14 & Baixo & 1 & $3 \%$ & 1 \\
\hline 17 & Baixo & 2 & $7 \%$ & 2 \\
\hline 20 & Baixo & 6 & $21 \%$ & - \\
\hline \multicolumn{4}{|c|}{$\sum$ CVD } & 23 \\
\hline \multicolumn{4}{|c|}{ Valor corrigido - VDC } & 13 \\
\hline \multicolumn{4}{|c|}{$I C P=100-V D C$} & 87 \\
\hline \multicolumn{4}{|c|}{ CONCEITO } & EXCELENTE \\
\hline
\end{tabular}

\subsection{Cálculo do ICP da Faixa 4 - Sentido Derby-Centro}

A Faixa 4 encontra-se no corredor central de ônibus, no sentido Derby-Centro, e assim como a Faixa 3 recebe constantemente um alto volume de cargas, devido ao peso do transporte coletivo, mas devido a importância da via, é sempre feita sua manutenção e troca de placas, que resultam no excelente resultado do ICP.

Tabela 6: ICP da Faixa 4

\begin{tabular}{|c|c|c|c|c|}
\hline \multicolumn{5}{|c|}{ ICP Faixa 4} \\
\hline $\begin{array}{c}\text { Tipo } \\
\text { de } \\
\text { defeito }\end{array}$ & $\begin{array}{c}\text { Grau de } \\
\text { severidade }\end{array}$ & $\begin{array}{c}\mathrm{N}^{\circ} \text { de } \\
\text { placas } \\
\text { afetadas }\end{array}$ & $\begin{array}{c}\% \text { de } \\
\text { placas } \\
\text { afetadas }\end{array}$ & $\begin{array}{c}\text { Valor } \\
\text { deduzível } \\
\text { (CVD) }\end{array}$ \\
\hline 5 & Médio & 21 & $72 \%$ & 4 \\
\hline 7 & Baixo & 1 & $3 \%$ & 3 \\
\hline 9 & Baixo & 2 & $7 \%$ & - \\
\hline 10 & Médio & 23 & $79 \%$ & 10 \\
\hline 12 & Baixo & 1 & $3 \%$ & 4 \\
\hline 16 & Baixo & 1 & $3 \%$ & 1 \\
\hline 17 & Baixo & 4 & $14 \%$ & 3 \\
\hline 20 & Baixo & 12 & $41 \%$ & - \\
\hline \multicolumn{4}{|c|}{$\sum$ CVD } & 25 \\
\hline \multicolumn{4}{|c|}{ Valor corrigido - VDC } & 13 \\
\hline \multicolumn{4}{|c|}{$I C P=100-V D C$} & 87 \\
\hline \multicolumn{4}{|c|}{ CONCEITO } & EXCELENTE \\
\hline
\end{tabular}




\subsection{Cálculo do ICP da Faixa 5 - Sentido Derby-Centro}

Tabela 7: ICP da Faixa 5

\begin{tabular}{|c|c|c|c|c|}
\hline \multicolumn{5}{|c|}{ ICP Faixa 5} \\
\hline $\begin{array}{l}\text { Tipo } \\
\text { de } \\
\text { defeito }\end{array}$ & $\begin{array}{l}\text { Grau de } \\
\text { severidade }\end{array}$ & \begin{tabular}{|l|}
$\mathrm{N}^{\circ} \mathrm{de}$ \\
placas \\
afetadas
\end{tabular} & $\begin{array}{l}\% \text { de } \\
\text { placas } \\
\text { afetadas }\end{array}$ & $\begin{array}{l}\text { Valor } \\
\text { deduzível } \\
\text { (CVD) }\end{array}$ \\
\hline 1 & Baixo & 1 & $3 \%$ & 2 \\
\hline 5 & Médio & 19 & $66 \%$ & 4 \\
\hline 7 & Baixo & 1 & $3 \%$ & 3 \\
\hline 9 & Baixo & 1 & $3 \%$ & - \\
\hline 10 & Médio & 9 & $31 \%$ & 6 \\
\hline 16 & Baixo & 5 & $17 \%$ & 3 \\
\hline 17 & Baixo & 9 & $31 \%$ & 7 \\
\hline 18 & Baixo & 1 & $3 \%$ & 1 \\
\hline 20 & Baixo & 17 & $59 \%$ & - \\
\hline \multicolumn{4}{|l|}{$\sum$ CVD } & 26 \\
\hline \multicolumn{4}{|c|}{ Valor corrigido - VDC } & 14 \\
\hline \multicolumn{4}{|c|}{$I C P=100-V D C$} & 86 \\
\hline \multicolumn{4}{|c|}{ CONCEITO } & EXCELENTE \\
\hline
\end{tabular}

A Faixa 5, também é exclusiva para uso de transporte coletivo, e localiza-se no sentido DerbyCentro, entre as Faixas 4 e 6 . É observado uma maior incidência de pequenos buracos, a maioria deles por conta da retirada dos tachões ali instalados, e outros por conta do desgaste superficial das placas. Lembrando que os buracos são apenas catalogados, não entrando no cálculo do ICP. Observando a tabela 7, conclui-se que a Faixa 5 tem conceito excelente.

\subsection{Cálculo do ICP da Faixa 6 - Sentido Derby-Centro}

Tabela 8: ICP da Faixa 6

\begin{tabular}{|c|c|c|c|c|}
\hline \multicolumn{5}{|c|}{ ICP Faixa 6} \\
\hline $\begin{array}{l}\text { Tipo de } \\
\text { defeito }\end{array}$ & $\begin{array}{l}\text { Grau de } \\
\text { severidade }\end{array}$ & $\begin{array}{c}\mathrm{N}^{\circ} \text { de } \\
\text { placas } \\
\text { afetadas }\end{array}$ & $\begin{array}{c}\% \text { de } \\
\text { placas } \\
\text { afetadas }\end{array}$ & $\begin{array}{l}\text { Valor } \\
\text { deduzível } \\
\text { (CVD) }\end{array}$ \\
\hline 5 & Médio & 15 & $52 \%$ & 4 \\
\hline 10 & Médio & 23 & $79 \%$ & 10 \\
\hline 14 & Baixo & 1 & $3 \%$ & 1 \\
\hline 16 & Baixo & 1 & $3 \%$ & 1 \\
\hline 17 & Baixo & 3 & $10 \%$ & 3 \\
\hline 18 & Baixo & 1 & $3 \%$ & 1 \\
\hline 20 & Baixo & 12 & $41 \%$ & - \\
\hline \multicolumn{4}{|c|}{$\sum$ CVD } & 20 \\
\hline \multicolumn{4}{|c|}{ Valor corrigido - VDC } & 11 \\
\hline \multicolumn{4}{|c|}{$I C P=100-V D C$} & 89 \\
\hline \multicolumn{4}{|c|}{ CONCEITO } & EXCELENTE \\
\hline
\end{tabular}

A Faixa 6 é a do rolamento lateral, ao lado da calçada de pedestres, no sentido Derby-Centro. Com trafego de veículos de passeio, é a Faixa com maior ICP entre todas, apresentando com mais evidência desgaste superficial e falha na selagem das juntas.

\subsection{Cálculo do ICP Geral e gráfico comparativo}

Como era de se esperar, devido aos resultados individuais das faixas, o ICP geral teve conceito excelente. A Avenida Conde da Boa vista é uma via de grande importância, que passa sempre por manutenções, recuperações e trocas de placas.

Se seguido todos os parâmetros construtivos e continuar sendo feitas as manutenções que a estrutura demanda o pavimento terá aproveitamento máximo da vida útil.

A partir da análise do gráfico é possível notar que os resultados de ICP das faixas foram bem próximos, sendo o menor resultado de valor 86 (Faixas 2, 5 e geral) e o maior resultado de valor 89 (Faixa 6). 
Tabela 9: ICP geral

\begin{tabular}{|c|c|c|c|c|}
\hline \multicolumn{5}{|c|}{ ICP GERAL } \\
\hline $\begin{array}{c}\text { Tipo } \\
\text { de } \\
\text { defeito }\end{array}$ & $\begin{array}{c}\text { Grau de } \\
\text { severidade }\end{array}$ & $\begin{array}{c}\mathbf{N}^{\circ} \text { de } \\
\text { placas } \\
\text { afetadas }\end{array}$ & $\begin{array}{c}\% \text { de } \\
\text { placas } \\
\text { afetadas }\end{array}$ & $\begin{array}{c}\text { Valor } \\
\text { deduzível } \\
\text { (CVD) }\end{array}$ \\
\hline 1 & Baixo & 2 & $1 \%$ & 1 \\
\hline 2 & Baixo & 1 & $1 \%$ & 1 \\
\hline 5 & Médio & 92 & $53 \%$ & 4 \\
\hline 7 & Baixo & 7 & $4 \%$ & 3 \\
\hline 8 & Baixo & 1 & $1 \%$ & 1 \\
\hline 9 & Baixo & 13 & $7 \%$ & - \\
\hline 10 & Médio & 111 & $64 \%$ & 9 \\
\hline 12 & Baixo & 1 & $1 \%$ & 1 \\
\hline 14 & Baixo & 5 & $3 \%$ & 1 \\
\hline 16 & Baixo & 9 & $5 \%$ & 1 \\
\hline 17 & Baixo & 28 & $16 \%$ & 4 \\
\hline 18 & Baixo & 2 & $1 \%$ & 1 \\
\hline 20 & Baixo & 65 & $37 \%$ & - \\
\hline \multicolumn{4}{|c|}{$\sum$ CVD } & 27 \\
\hline \multicolumn{4}{|c|}{ Valor corrigido - VDC } & 14 \\
\hline \multicolumn{4}{|c|}{$I C P=100-V D C$} & 86 \\
\hline \multicolumn{4}{|c|}{ CONCEITO } & EXCELENTE \\
\hline
\end{tabular}

\section{Gráfico ICP das Faixas}

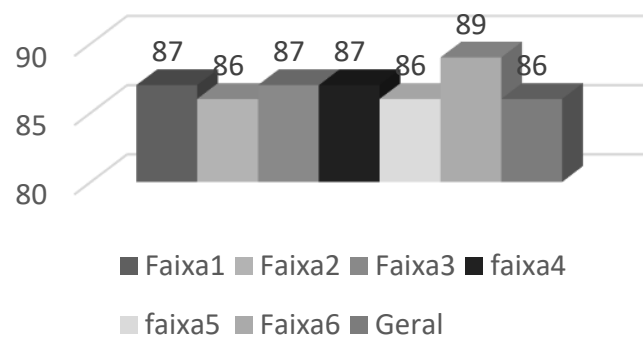

Gráfico 1: Gráfico comparativo dos ICP encontrados

\section{Defeitos Recuperáveis Irrecuperáveis}

Segundo DNIT [7] nos pavimentos rígidos tem sido mais frequente a ocorrência de defeitos localizados, associados a uma ou várias causas, ao invés da degradação uniforme de todo trecho construído.

Os principais fatores causadores da degradação de um pavimento rígido são:

- Deficiência da capacidade de suporte da fundação
- Drenagem mal projetada ou mal executada

- Excesso de carga dos veículos

- Execução deficiente ou falta de manutenção do material selante das juntas

Os defeitos podem ser considerados recuperáveis, ou seja, não implicam na remoção parcial ou total da placa de concreto ou podem ser irrecuperáveis, cuja solução é a demolição da placa defeituosa e a execução de uma nova placa de pavimento, em alguns casos é exigida a remoção e recuperação da própria fundação do pavimento e da sua sub-base.[7]

\subsection{Defeitos Recuperáveis}

São aqueles cujas causas que the deram origem podem ser eliminadas após sua recuperação. Em princípio todo defeito que apresenta baixo ou médio grau de severidade pode ser recuperado, mas a depender da quantidade e extensão dos defeitos existentes em uma placa torna-se inviável sua recuperação.

Defeitos decorrentes de falha na fundação, subdimensionamento da espessura das placas, emprego de materiais inadequados e de concreto de má qualidade são de recuperação inviável ou ineficiente, mesmo que apresentem baixo grau de severidade.

\subsection{Defeitos Irrecuperáveis}

Quando não for possível, por meio de reparação dos defeitos, eliminar as causas que the deram origem, tais como deficiências na fundação; subdimensionamento ou fadiga do pavimento; deficiência no dispositivo de transmissão de cargas nas jun tas; e a grande extensão e quantidade de defeitos em uma placa, considera-se irrecuperável, devendo a placa ser demolida parcial ou totalmente, sendo refeita. São defeitos considerados críticos e, geralmente, aqueles que apresentam alto grau de severidade.

\section{Conclusão}

Para garantir o funcionamento satisfatório de um pavimento rígido é fundamental que seja permanentemente feito o controle da ocorrência de defeitos, além do acompanhamento da sua evolução no tempo, executando-se prontamente os reparos que assegurem a manutenção da condição estrutural e funcional do pavimento.

A utilização de pavimentos rígidos na malha rodoviária conta com a vantagem da durabilidade, se

http: / / dx.doi.org/10.25286/repa.v4i1.584 
comparado com o pavimento flexível.

Um exemplo disso é o trecho analisado da Avenida Conde da Boa Vista, com placas antigas, mas que ainda assim encontram-se em excelente estado de conservação, devido as suas manutenções e trocas de placas recentes, mas com alguns defeitos, que se não passarem por recuperações e manutenções de tempos em tempos, irão se agravar, podendo modificar completamente o conceito do trecho e a vida útil da estrutura.

O ICP apresenta metodologia simples e fácil, que resulta em um número que qualifica o estado de conservação da via, estabelecendo dados importantes para medidas de prevenção, manutenção e recuperação do pavimento.

\section{Referências}

[1] A. Minhoto, Consideração da Temperatura no Comportamento à Reflexão de Fendas dos Reforços de Pavimentos Rodoviários Flexíveis, Braga: Escola de Engenharia, Universidade do Minho, 2005.

[2] HELENE, P. 2007. Rehabilitación y Mantenimento das Estructuras de Concreto. São Paulo, Paulo Helene \& Fernanda Pereira, $775 \mathrm{p}$

[3] MAGGI, P.L.O.; CASTELLANO, T.G. Patologia em Pavimentos Rígidos. Anais do VI Simposio EPUSP sobre estruturas de concreto.2006.

[4] OLIVEIRA, P.L.; PINHEIRO, L.M.Projeto Estrutural de Pavimentos Rodoviários e de Pisos Industriais de Concreto. Dissertação de Mestrado. Universidade de São Paulo. São Carlos. 2000.

[5] DEPARTAMENTO NACIONAL DE INFRAESTRUTURA DE TRANSPORTES (DNIT). 2005. DNIT IPR-714: Manual de Pavimentos Rígidos. Rio de Janeiro, Departamento Nacional de Infra-Estrutura De Transportes, $234 \mathrm{p}$.

[6] DNIT 061/2004-TER: Pavimento Rígido Defeitos: Terminologia. Rio de Janeiro. 2004.

[7] DEPARTAMENTO NACIONAL DE INFRAESTRUTURA DE TRANSPORTES (DNIT). 2010. DNIT IPR-737: Manual de Recuperação de Pavimentos Rígidos. Rio de Janeiro, Departamento nacional de Infra-Estrutura de Transportes, 140p.

[8] DNIT 062-PRO: Pavimento Rígido Avaliação Objetiva - Procedimento. Rio de Janeiro. 2004.

[9] DNIT 060-PRO: Pavimento Rígido Inspeção Visual - Procedimento. Rio de Janeiro. 2004.

[10] DNIT 063-PRO: Pavimento Rígido Avaliação Subjetiva -Procedimento. Rio de Janeiro. 2004. 